\title{
Improved method for estimating blood sugar
}

NIYAM CHARAN SHARMA AND BIMAL KUMAR SUR
From the Department of Physiology, G.S.V.M.
Medical College, Kanpur (India)

True blood-sugar estimation is performed routinely by the Asatoor and King method (1954) in a large number of hospital laboratories. Their method is a colorimetric modification of one (Harding and Downs, 1933) of the most accurate iodometric titration procedures, in which Received for publication 8 December 1965.

Simple method for the isolation of 17 -oxosteroid glucuronides from urine-continued

tion of this may be that the renal clearance of the sulphates is a much slower process (Bongiovanni, 1958).

As anticipated, the major part of the recovered 17-oxosteroids was accounted for as androsterone glucuronide, but a large amount was also conjugated with sulphuric acid. Schneider and Lewbart (1959) found that only a small amount of administered androsterone was converted to isoandrosterone but in this experiment a large proportion of the administered androsterone was converted to isoandrosterone. This steroid was solely conjugated with sulphuric acid and its percentage excretion was fairly constant and was not dependent on the total output of the steroid. We failed to detect in either the glucuronide or the sulphate fraction any androstan-3,17dione, which is the metabolic intermediate between androsterone and isoandrosterone. There was also no conversion to aetiocholanolone.

I wish to thank Dr. J. M. Tanner for creating the facilities to carry out this work and Dr. R. W. H. Edwards for helpful advice. The work was supported by a grant from the Medical Research Council.

\section{REFERENCES}

Baulieu, E. E. (1960). C.R. Acad. Sci. (Paris), 251, 1421.

Bongiovanni, A. M. (1958). J. clin. Invest., 37, 1342.

Crépy, O., Jayle, M. F., and Meslin, F. (1957). Acta endocr. (Kbh.), 24, 233.

Edwards, R. W. H., and Kellie, A. E. (1956). Chemy Ind., 250.

Gupta, D. (1963). Nature (Lond.), 200, 574.

, and Tanner, J. M. (1965). Biochem. J., 96, 25 P.

Hadd, H. E. (1958). Abstr. Meeting of Amer. Chem. Soc., 54C.

$\longrightarrow$, and Dorfman, R. I. (1963). J. biol. Chem., 238, 907.

Kamil, I. A., Smith, J. N., and Williams, R. T. (1953). Biochem. J. $53,129$.

Schneider, J. J., and Lewbart, M. L. (1959). Recent Progr. Hormone Res., 15, 201.

Staib, W., and Doenges, K. (1960). Hoppe-Seylers Z. physiol. Chem., 319, 233.

Vogel, A. I. (1948). Text Book of Practical Organic Chemistry. Longmans, London.

Zimmermann, W. (1935). Hoppe-Seylers Z. physiol. Chem., 233, 257. reduced copper is oxidized to cupric ions by means of iodine. If no necessary allowance has been made, the cupric ions formed would be completely reduced and precipitated as cuprous iodide in the presence of an excess of soluble iodide in the reagent. Probably to check this reduction by iodide, Harding and Downs (1933) employed potassium oxalate in their alkaline reagent because oxalate inhibits more or less completely the reaction of the cupric salt with soluble iodides by forming alkali os cuprioxalate which dissociates to give cuprioxalate anions $\vec{\circ}$ (Elbs, 1917; Shaffer and Hartmann, 1921; DeLong, 1927). Asatoor and King (1954), without considering the funda- $\bar{\omega}$ mental role of potassium oxalate, retained it in the alkaline reagent in their colorimetric modification of the method which makes no use of iodometry. It appears $\vec{\oplus}$ that potassium oxalate plays no role in the colorimetric os method and, therefore, we modified the methodof A satoor and King by omitting it in their alkaline reagent.

\section{MATERIALS AND METHODS}

In addition to the reagents used by Asatoor and King (1954), a new modified alkaline reagent containing $25 \mathrm{~g}$. $\mathrm{NaHCO}_{3}, 20$ g. $\mathrm{Na}_{2} \mathrm{CO}_{3}$, and 12 g. Rochelle salt $\left(\mathrm{KNaC}_{4} \mathrm{H}_{4} \mathrm{O}_{6} .4 \mathrm{H}_{2} \mathrm{O}\right)$ per litre has also been introduced.

For estimation of glucose in standard solutions, the method described by Asatoor and King (1954) for true blood sugar determination, was used in its original form and in the form utilizing the new alkaline reagent. The optical densities of the blue solutions obtained with phosphomolybdic acid reagent were read on a Klett Summerson photoelectric colorimeter using a 66-red filter. The strength of glucose solutions used has been expressed as corresponding to milligrams per $100 \mathrm{ml}$ blood and not as its actual concentration.

\section{RESULTS AND DISCUSSION}

Figure 1 shows that the blue colour formed by the Asatoor and King method obeys Beer's law for glucose solutions of concentrations above $100 \mathrm{mg}$. per $100 \mathrm{ml}$. and not below this strength. In the range 40 to $80 \mathrm{mg}$. glucose per $100 \mathrm{ml}$., values obtained are lowered to the extent of 14 to $32 \%$. Apparently for this reason, Asatoor and King introduced a second glucose standard (corresponding to $80 \mathrm{mg}$. per $100 \mathrm{ml}$. blood) in their method. A fasting normal blood sugar value of around $60 \mathrm{mg}$. per $100 \mathrm{ml}$. would be about $15 \%$ too low even if a glucose standard of $80 \mathrm{mg}$. per $100 \mathrm{ml}$. is used. Correct values in this region can, however, be obtained only if the readings of the test and standard are close to each other. While using this method, we frequently observed low normal blood-sugar values and it appears from the results (Fig. 1) that the lack of linearity in this region might be responsible for low normal blood-sugar values.

In the improved method omitting potassium oxalate, the optical density recorded was proportional to the concentration of glucose even in solutions as dilute as $20 \mathrm{mg}$. per $100 \mathrm{ml}$. (Fig. 1). Correct values for blood sugar can, therefore, be obtained using a single glucose standard.

Dilution of a stock molybdenum blue solution shows 


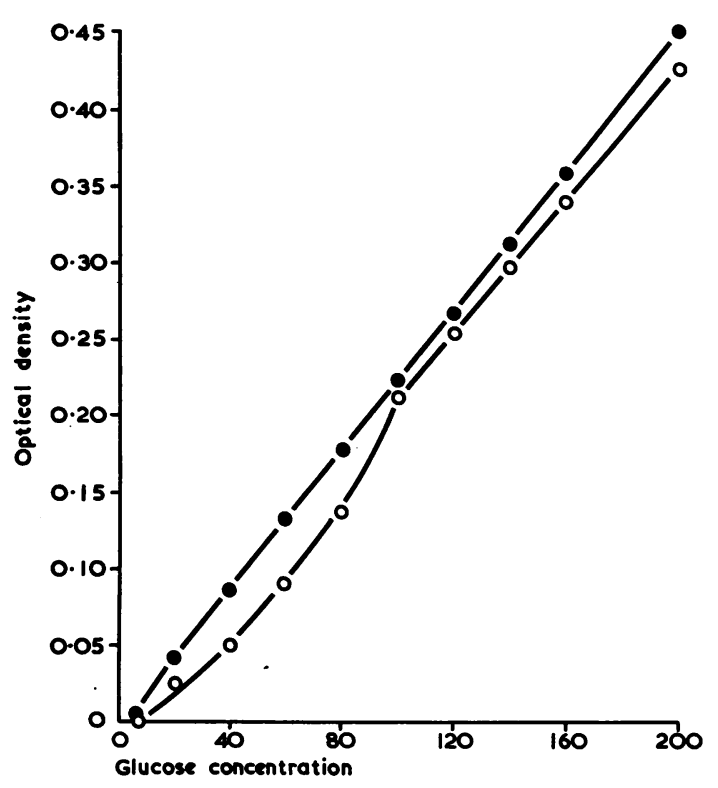

FIG. 1

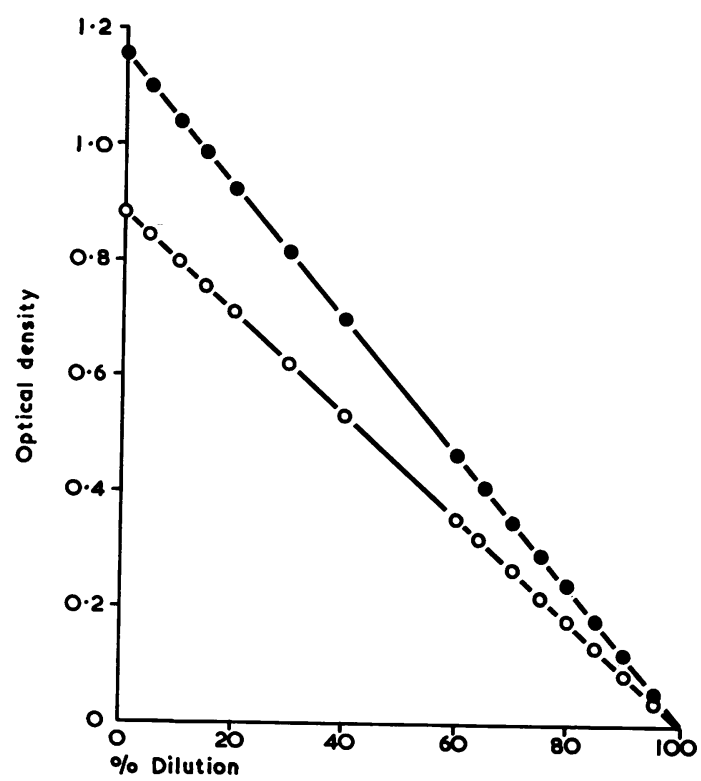

FIG. 2

FIG. 1. The change in optical density with the change in glucose concentration by the Asatoor and King method (o-o-o-o) and the modified Asatoor and King method (o-0-0-0). Concentration of glucose solution is expressed as corresponding to miligrams per $100 \mathrm{ml}$. blood.

FIG. 2. The change in optical density of the molybdenum blue solution with dilution by the Asatoor and King method (o-o-o-o) and the modified Asatoor and King method (o-o-o-o). The stock molybdenum blue for dilution was obtained with a glucose solution of strength $5 \mathrm{mg}$. per $100 \mathrm{ml}$. (corresponding to $400 \mathrm{mg}$. per $100 \mathrm{ml}$. blood.)

that Beer's law is obeyed in both the methods (Fig. 2). The low optical density obtained, particularly with dilute glucose solutions in the method of Asatoor and King, is not, therefore, due to an inherent failure of the molybdenum blue solution to obey Beer's law, but presumably due to reoxidation of $\mathrm{Cu}^{+}$to $\mathrm{Cu}^{++}$by atmosphericoxygen. This reoxidation of $\mathrm{Cu}^{+}$is relatively more important in low sugar concentrations. The presence of potassium oxalate in the modified Harding solution B used by Asatoor and King (1954) in some way increases re- oxidation of $\mathrm{Cu}^{+}$which results in lowered blood sugar values.

Our thanks are due to Dr. G. Sur for valuable suggestions.

\section{REFERENCES}

Asatoor, A. M., and King, E. J. (1954). Biochem. J., 56, 44P.

King, E. J., and Wootton, I. D. P. (1956). Microanalysis in Medical Biochemistry, 3rd ed., p. 25-27. Churchill, London.

DeLong, W. A. (1927). J. biol. Chem., 72, 731.

Elbs, K. (1917). Z. Electrochem., 23, 147.

Harding, V. J., and Downs, C. E. (1933). J. biol. Chem., 101, 487.

Shaffer, P. A., and Hartmann, A. F. (1921). Ibid., 45, 365. 